\title{
A ATIVIDADE DE ESTUDO COMO UM PROCESSO PROPULSOR DO DESENVOLVIMENTO PSÍQUICO
}

\author{
Antonio Paulino de Oliveira Junior ${ }^{1}$ \\ José Carlos Miguel²
}

\begin{abstract}
RESUMO
Este estudo apresenta uma síntese teórica de uma pesquisa bibliográfica acerca da atividade de estudo e o seu papel fundamental para o desenvolvimento psíquico de sujeitos em processos educativos. Trata-se da atividade humana como um princípio fundamental da formação, constituição e desenvolvimento histórico do ser humano e sua inter-relação com o ensino e a aprendizagem. Foram abordados, neste texto, os postulados teóricos encontrados em autores como Leontiev, Davidov ${ }^{3}$ e Elkonin, os quais corroboraram para o desenvolvimento da teoria da atividade e o delineamento da atividade de estudo como um fator educativo e de desenvolvimento humano. $O$ estudo mostrou que a atividade de estudo, independente do período da vida, dispõe ao sujeito um desenvolvimento que o leva a operar com os conceitos científicos e objetos circundantes por intermédio de ações mentais. Ao chegar a esse patamar de desenvolvimento, o sujeito não somente modifica a forma como interage com o mundo, mas também transforma o meio circundante. Nesse sentido, chegou-se ao entendimento de que nesse ponto concentra-se o cerne da perspectiva histórico-cultural, o qual pressupõe uma superação ou mudança das condições postas por meio desse movimento dialético presente na estrutura da atividade especificamente humana.
\end{abstract}

Palavras-chave: Teoria histórico-cultural. Atividade de estudo. Desenvolvimento psíquico.

\section{THE LEARNING ACTIVITY AS A PROCESS OF PROPULSION OF PSYCHIC DEVELOPMENT}

\begin{abstract}
This study is a theoretical synthesis of a bibliographic research about the learning activity and its fundamental role for the psychic development of subjects in educational processes. It is human activity as a fundamental principle of the formation, constitution and historical development of the human being and its interrelationship with teaching and learning. Theoretical postulates found in such authors as Leontiev, Davidov and Elkonin, were corroborated for the development of the theory of activity and the delineation of the learning activity as an educational and human development factor. The study pointed out that the learning activity, independent of the period of life, provides the subject with a development that leads him to operate with scientific concepts and surrounding objects through mental actions. Upon reaching this level of development, the subject not only modifies the way he interacts with the world, but also transforms the surrounding environment. In this sense, it was reached the understanding that this point concentrates the core of the historical-cultural perspective, which presupposes an overcoming or change of the conditions put, by means of this dialectical movement present in the structure of the specifically human activity.
\end{abstract}

Keywords: Learning activity. Historical-cultural theory. Psychic development.

RECEBIDO EM: 18/12/2018

ACEITO EM: 26/2/2019

\footnotetext{
${ }^{1}$ Pedagogo vinculado ao Departamento de Educação da UTFPR, Campus Campo Mourão/PR. Doutorando do Programa de Pós-Graduação em Educação da Unesp, Campus de Marília/SP. http://lattes.cnpq.br/1612325151317293. https://orcid.org/0000-0002-9315-0977. antonjunior@gmail.com

2 Professor-associado vinculado ao Departamento de Didática e ao Programa de Pós-Graduação em Educação da Unesp, Campus de Marília/ SP. http://lattes.cnpq.br/9493055898353294. https://orcid.org/0000-0001-9660-3612. jocarmi@terra.com.br

${ }^{3}$ Utilizaremos a grafia Davidov, mas manteremos a grafia original quando se tratar de referências.
} 
No presente trabalho realizaremos uma pesquisa bibliográfica, de cunho teórico, que possibilite analisar o processo de desenvolvimento da atividade de estudo, perpassando por suas bases teóricas e pelos princípios teóricos acerca da categoria da atividade humana, a qual podemos considerar um dos fatores mais importantes para o desenvolvimento histórico da humanidade.

A atividade foi um objeto de estudo fundamental para o delineamento das pesquisas realizadas por A. N. Leontiev (1903-1979), que definiu os princípios gerais das forças motoras no processo de desenvolvimento psíquico na criança, colaborando com o desenvolvimento de pesquisas e estudos no campo da educação, ensino e aprendizagem.

Ao partir do mesmo referencial teórico, com base nos princípios gerais da atividade humana, V. V. Davidov (1930-1998) debruçou-se, ao longo da segunda metade do século 20, em seus experimentos acerca da atividade de estudo no processo de desenvolvimento do pensamento teórico nos estudantes dos primeiros anos de escolaridade.

Dessa forma, ambos os autores desenvolveram pesquisas que, direta ou indiretamente, estão relacionadas entre si e com o campo investigativo da educação, e, mediante a realização deste ensaio teórico, pretenderemos identificar quais são os princípios teóricos fundamentais de cada autor, enfatizando a Atividade de Estudo e seus desdobramentos para o ensino, aprendizagem e desenvolvimento humano.

Para a realização de uma discussão que possa contribuir com a área educacional brasileira, bem como a prática docente na Educação Básica e formação de professores, selecionamos apenas fontes primárias dos principais autores soviéticos acerca do tema, buscando apresentar seus pontos de vista e perspectivas teóricas que, por serem pouco difundidas na comunidade acadêmica e profissional, abrem margem para a ampliação da discussão sobre problemas enfrentados pela educação no país.

Nesse sentido, apresentaremos a seguir um compilado sobre os postulados teóricos delineados por Leontiev, Davidov e seus colaboradores, destacando a influência da atividade de estudo em todos os períodos do desenvolvimento, bem como sua estruturação e objetivos a serem alcançados.

\section{AS FORÇAS MOTORAS DO DESENVOLVIMENTO PSÍQUICO}

Uma das principais questões que nortearam os estudos dos autores ligados à Teoria Histórico-cultural foi a constituição do homem como ser social, produto das interações sociais, que, ao se apropriar da cultura humana, mediada pelos instrumentos físicos e simbólicos, adquire capacidades e aptidões especificamente humanas que o distingue de qualquer outra espécie.

Essa perspectiva de desenvolvimento humano apresenta-se de forma contrária às concepções da Psicologia Tradicional pautada em duas vertentes antagônicas: 1) que o desenvolvimento ocorre naturalmente por uma determinação biológica, na qual a aprendizagem e o desenvolvimento se dão por etapas, respeitando o amadurecimento do organismo; 2) que o desenvolvimento é um produto do espaço em que se vive, de 
forma que a personalidade seja moldada pelo meio ambiente e pelos demais fenômenos externos ao organismo, sem considerar a herança genética e as características biológicas dos sujeitos (LEONTIEV, 2004).

Na perspectiva da Teoria Histórico-cultural, o desenvolvimento não se dá naturalmente por um determinismo biológico e tampouco pela determinação externa e do meio ambiente. Para Leontiev (2004), o homem é formado em um processo de atividade capaz de estabelecer uma interação entre suas características biológicas e o meio social.

[...] as aptidões e funções especificamente humanas se formam no processo de apropriação pelo indivíduo do mundo dos objetos e fenômenos humanos e que o seu substrato material é constituído por sistemas de reflexos sensíveis formados pela vida (p. 273).

Dessa forma, o autor compreende que as aptidões e faculdades inerentes à formação do homem, como a memória, a atenção arbitrária, o pensamento abstrato e o raciocínio lógico, não podem se formar somente a partir de uma determinação biológica ou da relação direta do sujeito com o meio ambiente.

Vigotski (2010) compreende que o desenvolvimento das faculdades humanas ocorre por meio da interação das estruturas primárias do pensamento infantil com uma estrutura superior, que é um fator característico do pensamento adulto. $O$ objetivo dessa interação é que a criança, dotada de uma estrutura elementar (aptidões biológicas) se aproprie de uma estrutura superior (faculdades e aptidões humanas desenvolvidas historicamente).

Nesse ponto de vista, compreendemos que o desenvolvimento ocorre mediante fatores externos ao organismo humano. Isto é, o espaço social configura-se na fonte de todas as especificidades humanas. "No meio existe uma forma ideal ou final que interage com a forma primária da criança e, em resultado, uma dada forma de ação se torna uma aquisição interna da criança, torna-se dela própria, torna-se uma função de sua personalidade" (VIGOTSKI, 2010, p. 699).

Nesse sentido, há uma influência exercida pelo meio social com relação ao desenvolvimento psíquico, mas não podemos reduzir essa compreensão a qualquer tipo de interação com o meio. Para ocorrer o desenvolvimento é necessária a existência de uma forma final superior que possibilite à criança atingir estágios mais desenvolvidos de pensamento. Por exemplo, supondo que uma criança vivesse isoladamente de pessoas adultas ou convivesse apenas com seus pares, poderíamos inferir que seu desenvolvimento seria bastante elementar, mesmo que o meio ambiente estivesse rodeado de objetos físicos e simbólicos, os quais, de certo modo, não teriam significado algum para as crianças.

As aquisições do desenvolvimento histórico das aptidões humanas não são simplesmente dadas aos homens nos fenômenos objetivos da cultura material e espiritual que os encarnam, mas são aí apenas postas. Para se apropriar destes resultados, para fazer deles as suas aptidões, "os órgãos da sua individualidade", [...], o ser humano, deve entrar em relação com os fenômenos do mundo circundante através 
de outros homens, isto é, num processo de comunicação com eles. Assim, a criança aprende a atividade adequada. Pela sua função este processo é, portanto, um processo de educação (LEONTIEV, 2004, p. 290).

O caráter educativo da atividade humana, delineado por Leontiev (2004), é fundamental para possibilitar que as crianças possam relacionar-se em um processo ativo com os demais adultos, possibilitando a formação das aptidões físicas e mentais necessárias para dar continuidade ao avanço da história social da humanidade.

Para a geração precedente ter acesso ao patrimônio material e intelectual desenvolvido pela humanidade, é necessária a interação social com a geração passada, o que remete à importância da educação para a civilização humana. Os instrumentos físicos e simbólicos, mediadores da atividade, dissociados das relações sociais, não possibilitam a apropriação do conhecimento pela criança. Sem a presença do adulto para orientar, organizar e participar das atividades com a criança, os conhecimentos objetivados não serão apropriados.

Com base nesses pressupostos ativos do desenvolvimento da criança, Leontiev (2004) buscou investigar quais são as forças motoras do desenvolvimento, definindo a categoria da atividade como um fator predominante no processo de apropriação da cultura e desenvolvimento social da humanidade.

A atividade, para Leontiev (2001), configura-se em um pilar central para a compreensão das forças motoras do desenvolvimento psíquico das crianças. É importante salientarmos, porém, que não é qualquer tipo de atividade à qual o autor se refere.

Por esse termo designamos apenas aqueles processos que, realizando as relações do homem com o mundo, satisfazem uma necessidade especial correspondente a ele. Nós não chamamos de atividade um processo como, por exemplo, a recordação, porque ela, em si mesma, não realiza, via de regra, nenhuma relação independente com o mundo e não satisfaz qualquer necessidade especial (p. 68).

Para que uma atividade possa ser decisiva para o desenvolvimento de uma criança é fundamental que, primeiramente, esteja relacionada a uma necessidade interior do sujeito que, por sua vez, é caracterizada e materializada por um objeto e, por conseguinte, este esteja diretamente referido ao objetivo do sujeito, isto é, o motivo.

Esse processo ativo do desenvolvimento psíquico está diretamente relacionado ao estágio e ao nível de desenvolvimento, fator esse que é determinado pelo lugar ocupado pelo sujeito na estrutura das relações sociais.

Para Leontiev (2004), a cada etapa do desenvolvimento a criança ocupa determinado lugar nas relações sociais. A partir do momento em que cresce e se desenvolve, suas relações sociais se ampliam, modificando o lugar ocupado nas relações sociais e reorganizando suas funções psíquicas.

O que determina a modificação do lugar ocupado pela criança? Para Leontiev (2004), são as condições da vida social que exigem da criança a mudança da atividade a partir da ampliação de suas relações sociais. Essas transições configuram-se, segundo o autor, pelas crises do desenvolvimento que ocorrem aos três anos (inserção da criança na educação infantil), aos sete anos (início da idade escolar) e na adolescência (início da vida adulta e da atividade profissional). 
Dessa forma, quando se modifica o lugar ocupado pela criança também se modificam as atividades, e essa ruptura de um estágio para outro é que impulsiona o desenvolvimento. A atividade realiza-se de acordo com o lugar ocupado por ela nas relações sociais, decorrentes do meio em que ela vive. Nos primeiros anos de vida, a criança realiza atividades para conhecer o mundo, identificando fenômenos e objetos existentes. $\mathrm{Na}$ idade escolar ela desenvolve atividades voltadas para o estudo e o emprego arbitrário do pensamento, tomando uma nova postura em relação à escola. Na adolescência, ela passa a empregar o pensamento teórico e a participar mais excessivamente da vida adulta, da atividade profissional e de preocupações às quais ela não dava atenção no estágio anterior.

É importante destacarmos que, de acordo com Leontiev (2004), não são todas as atividades que propiciam o desenvolvimento da criança. Devemos considerar algumas atividades alinhadas a determinados estágios do desenvolvimento e que são propulsoras desse processo. Leontiev (2004, p. 312) denominou de atividade dominante "[...] aquela cujo desenvolvimento condiciona as principais mudanças nos processos psíquicos da criança e as particularidades psicológicas da sua personalidade num dado estágio do seu desenvolvimento".

O estágio de desenvolvimento, portanto, assim como o lugar ocupado pela criança nas relações sociais, é determinado pela atividade dominante que, quando modificada, muda toda a estrutura do desenvolvimento da criança, o lugar ocupado e o estágio de seu desenvolvimento. Podemos usar como exemplos de atividade dominante o jogo para crianças da educação infantil, o estudo para os alunos em idade escolar e o trabaIho para a vida adulta.

Para compreender a mudança de uma atividade dominante para outra, Leontiev (2004) investiga a relação existente entre atividade, ação e operação.

Como podemos diferenciar a atividade da ação? Elas são sinônimas?

Leontiev (2004) destaca que há uma relação peculiar entre a atividade e a ação, mas não podem ser consideradas sinônimas ou equivalentes. No processo psicológico, o qual corriqueiramente denominamos atividade, pode acontecer de o objeto do processo coincidir ou não com o motivo do sujeito que o realiza.

Essa característica dos processos psicológicos é o que diferencia a atividade da ação, em que a primeira tem o objeto diretamente ligado ao motivo que a incita, envolvendo, em sua estrutura, diversas ações e operações. A ação, por outro lado, não coincide diretamente com o motivo e, por essa razão, constitui-se em um componente dentro da atividade.

Designamos pelo termo de atividade os processos que são psicologicamente determinados pelo fato de aquilo para que tendem no seu conjunto (o seu objeto) coincidir sempre com o elemento objetivo que incita o paciente a uma dada atividade, isto é, com o motivo (LEONTIEV, 2004, p. 315).

Para compreendermos melhor a diferenciação entre atividade e ação, podemos tomar como exemplo a situação da mãe de uma criança que a obriga a estudar duas horas de piano todos os dias para ter direito a brincar com seus amigos. O estudo do instrumento é feito corretamente pela criança, porém não está relacionado diretamen- 
te com o motivo, cujo interesse é brincar com seus amigos. O estudo, portanto, é uma ação para que ela possa brincar. Com o passar do tempo, a mesma passa a se interessar pela música e, independente da condição de brincar, ela estuda três horas de piano por dia com o objetivo de melhorar sua técnica e execução. Nesse caso, o estudo, que antes era uma ação nessa situação, torna-se uma atividade na qual o estudo do piano (objeto) coincide diretamente com o interesse da criança em aprender (motivo).

O elemento fundamental para que a criança possa modificar sua atividade dominante, de acordo com Leontiev (2004), é a criação de novos motivos, uma vez que esse tem a capacidade de mover as crianças para a realização consciente das atividades e impulsionar o seu desenvolvimento psíquico.

Como parte da análise da estrutura da atividade, Leontiev (2004) também apresenta o papel das operações no decurso do desenvolvimento humano, bem como sua relação com a ação.

Por operação, entendemos o modo de execução de uma ação. A operação é o conteúdo indispensável de toda a ação, mas não se identifica com a ação. Uma só e mesma ação pode realizar-se por meio de operações diferentes, e inversamente, ações diferentes podem ser realizadas pelas mesmas operações. Isto explica-se pelo fato de que enquanto uma ação é determinada pelo seu fim, as operações dependem das condições em que é dado este fim (p. 323).

As operações são as possibilidades existentes para a realização de uma determinada ação e, portanto, dinamicamente integram-se a ela. Na medida em que as operações se automatizam e, por conseguinte, deixa de exigir uma atenção voluntária por parte da criança, abre espaço para uma nova ação que exige outras operações.

Cada operação aparece pela primeira vez para a criança como uma ação, até mesmo porque ela ainda não a domina e necessita dar-lhe atenção. Quando a criança passa a dominar uma determinada ação, esta, por sua vez, passa a ser uma operação, possibilitando a realização de ações mais complexas.

Tomamos como exemplo o ensino da matemática que, nos primeiros anos de escolarização, exige do aluno a aprendizagem das quatro operações básicas: adição, subtração, multiplicação e divisão. Nesse período, o aluno terá como ação o estudo desses conteúdos, tomando toda a sua atenção e dedicação para a compreensão do conhecimento. Para um estudante de Engenharia, porém, que tem como ação a realização de um cálculo de diferencial e integral, pressupomos que ele tenha essas quatro operações básicas dominadas e as utilizará como operações para a realização da ação.

Dessa forma, à medida que a criança vai dominando e transformando as ações em operações, aumenta sua capacidade de realizar ações mais complexas, impulsionando o seu desenvolvimento. O desenvolvimento das operações, em certo ponto, pode se tornar um hábito e passar a ser executado, muitas vezes, de forma automática e inconsciente.

Essa é a dinâmica do desenvolvimento por meio do estudo da atividade desenvolvido por Leontiev (2004). São essas mudanças de ação para operação, de ação para atividade, de atividade dominante para outra, que são as forças motoras do desenvolvimento do psiquismo humano e, portanto, o próprio processo de humanização. 


\section{A ATIVIDADE DE ESTUDO E SUAS IMPLICAÇÕES PARA O DESENVOLVIMENTO PSÍQUICO}

\section{Bases Epistemológicas da Atividade de Estudo}

Na perspectiva da Teoria Histórico-Cultural, as bases teóricas, que dão sustentação ao estudo da categoria da atividade, consistem nas concepções materialista, histórica e dialética do conhecimento e, por conseguinte, é possível identificarmos a forte relação entre o pensamento e o material nos estudos de Davýdov (1982), sustentando que a formação do pensamento ocorre por meio de processos objetivos da atividade especificamente humana, a qual se formou, ao longo da história, mediante as relações sociais e com a natureza.

Para Davýdov (1982), o pensamento é uma atividade espiritual do homem com a qual está entrelaçada a prática e a vida social como forma de representação idealizada das relações do homem com os fenômenos externos.

O ideal é o reflexo da realidade objetiva nas formas da atividade subjetiva do homem social (em suas imagens internas, motivos e metas), que reproduz esse mundo objetivo. Isso se revela no consequente processo formativo do objeto necessário, realizado na atividade (DAVÝDOV, 1982, p. 286, tradução nossa).

Todo e qualquer objeto está posto no mundo por meio de sua forma material e somente é descoberto e utilizado pelo homem mediante as ações práticas e relações estabelecidas socialmente. A partir de então, sob o contato inicial com o objeto material, é que o homem se torna capaz de formular uma representação ideal e desenvolver o pensamento, o qual é atividade espiritual fundamental do homem.

Devemos levar em conta os pressupostos de Davýdov (1982) de que o pensamento se dá por diversas formas de atividades humanas, proporcionando aos sujeitos diferentes modos de conhecimentos, que tanto podem ser empíricos quanto teóricos.

Davýdov (1982) sustenta que a depender do tipo de atividade que o sujeito realiza sobre o objeto material e sua representação, é desencadeado um tipo determinado de pensamento. Por exemplo, a formação do pensamento empírico se dá mediante

[...] a formação de representações sensoriais gerais, diretamente entrelaçadas com a atividade prática, que cria as condições para uma atividade espiritual muito complexa, a qual é denominada de pensamento. Característico dele é a formação e utilização das palavras-denominações genéricas que permitem dar à experiência sensorial a forma de generalidade abstrata. Graças a essa forma se pode generalizar a experiência nos juízos e utilizá-la em deduções. Essa generalidade, baseada no princípio de identidade puramente formal e abstrata, é uma peculiaridade do pensamento empírico, [...]. Esse se constitui nos homens como forma verbalmente expressada e transformada da atividade dos "sentidos-teóricos", entrelaçada com a vida real. É um derivado direto da atividade objetiva-sensorial dos homens (DAVÝDOV , 1982, p. 296-297, tradução nossa).

A partir do exposto, compreendemos que o pensamento empírico se forma nas relações diretas com a realidade objetiva, apropriando-se do conhecimento imediato e disposto nas propriedades concretas e sensoriais do objeto. O pensamento empírico, no 
entanto, não pode ser subtraído como uma representação verbal qualquer, percebida imediatamente pelas vias sensoriais. É preciso reconhecer que há um pensamento racional, cognoscitivamente complexo e formado a partir de bases empíricas.

Com relação ao pensamento teórico, por sua vez, este é concebido por intermédio da formação de conceitos teóricos e científicos, os quais são refletidos em ações mentais. O pensamento teórico

[...] constitui uma idealização do aspecto fundamental da atividade prática-objetiva, a saber, da reprodução nela das formas gerais das coisas, de sua medida e de suas leis. Essa reprodução tem lugar na atividade laboral como em um singular experimento sensório-objetivo. Logo, esse experimento vai adquirindo cada vez mais um caráter cognoscitivo, permitindo que o homem passe com o tempo a experimentos mentais, atribua mentalmente aos objetos uma ou outra interação e determinada forma de movimento (DAVÝDOV, 1982, p. 299-300, tradução nossa).

Dessa forma, o pensamento teórico consiste em um tipo particular e característico de pensamento, com o qual o sujeito pode dispor de capacidades mentais superiores, as quais apresentam especificidades que são desenvolvidas pelas vias do conhecimento científico, abstrato e generalizado.

O pensamento teórico traz consigo um caráter integral do objeto de estudo e apresenta uma relação universal que garante ao sujeito compreender todas as suas múltiplas manifestações que, de modo geral, estão dispostas de forma interna. Para Davýdov (1982), o desenvolvimento do pensamento teórico inicia-se pela base empírica e sensorial dos objetos, mas necessita estabelecer uma relação de universalidade e de generalização.

A lógica dialética intrínseca ao pensamento teórico permite ao sujeito enxergar a essência de dado objeto estudado e compreender todo o seu processo de construção por meio de ações mentais que possibilitam a ascensão do abstrato ao concreto. $\mathrm{O}$ sujeito consegue operar mentalmente com um sistema conceitual que revela toda uma estrutura de formulação conceitual e o movimento dialético do abstrato ao concreto ou do objeto ao seu conteúdo teórico.

O pensamento teórico deve ser o objetivo a ser alcançado pelos processos educativos e, de acordo com Davídov (1988), a atividade de estudo, considerando toda a sua estrutura, é um caminho a ser percorrido pelos escolares para se chegar ao desenvolvimento do pensamento teórico.

\section{A Atividade de Estudo e a Periodização no Desenvolvimento}

A atividade de estudo e o desenvolvimento das funções psicológicas superiores, sobretudo o pensamento teórico, são fatores que pressupõem o envolvimento de ações do aluno com conceitos científicos desde o início do processo de escolarização, período este em que a atividade dominante da criança é a de estudo. 
Nesse estágio do desenvolvimento a atividade de estudo torna-se a ação mais importante para o desenvolvimento da criança, exigindo que ela assuma um novo patamar na estrutura das relações sociais, passando a ter mais responsabilidade em razão da inserção na escola e maior compreensão das leis que regulam as relações sociais, possibilitando maior aquisição da cultura produzida pela humanidade.

V. V. Davidov. D. B. Elkonin e A. Márkova são alguns autores que dedicaram suas pesquisas em torno da atividade de estudo, sobretudo com crianças no período dos primeiros anos de escolarização. A partir dos resultados de suas investigações, foi possível constatar e validar os pressupostos em relação à importância e à influência da atividade de estudo sob a formação das bases da consciência e do pensamento teórico.

Davidov $(1999$, p. 1) apresenta três elementos fundamentais para a definição de uma atividade de estudo:

Em primeiro lugar, ela contém todos os componentes enumerados do conceito geral de atividade. Em segundo lugar, estes componentes têm um conteúdo de objeto específico, que os distingue de qualquer outra atividade (por exemplo, da atividade de jogo ou de trabalho). Em terceiro, na atividade de estudo é obrigatório que haja o princípio criativo ou transformador.

Embora tenha todos os componentes de uma atividade em geral, destacada na estrutura definida por Leontiev (2004), a atividade de estudo não pode ser confundida com qualquer outro tipo de atividade, seja a de jogo ou de trabalho, justamente por trazer consigo os elementos de transformação e criação do sujeito.

Toda atividade humana carrega um caráter educativo, posto que crianças e adultos assimilam e se apropriam de diferentes conhecimentos por meio de variadas atividades. Não obstante, "[...] a atividade de estudo, incluindo em si os processos de aprendizagem, só se realiza quando esses processos transcorrem sob a forma de uma transformação objetiva deste ou daquele material" (DAVIDOV , 1999, p. 2). Desse modo, uma atividade de estudo envolve o elemento de transformação que ocorre tanto no objeto de estudo quanto no próprio sujeito.

Elkonin (1999) destaca a tarefa de estudo como um componente importante da atividade de estudo que, por ser comparada a uma tarefa concreta e prática, promove modificações no objeto de estudo, mas afirma que o principal objetivo é a autotransformação do sujeito. Para o autor, qualquer atividade prática tende a promover a modificação do objeto e, em certa medida, do sujeito, uma vez que, para isso, necessita da relação com o objeto real. Dessa forma, a atividade de estudo precisa, impreterivelmente, da presença de um objeto. Diferentemente das tarefas práticas, no entanto, os resultados e objetivos que se esperam estão relacionados às mudanças que serão projetadas para acontecer nos sujeitos.

Repkin (2014), da mesma forma, chama a atenção para o entendimento de que a atividade de estudo se diferencia de outras atividades realizadas por uma pessoa, justamente pelo fato de seu objetivo ser a transformação interna do sujeito, na qual são realizadas tarefas que resultam na autotransformação. Por outro lado, as demais atividades apresentam objetivos e resultados relacionados às mudanças externas ao sujeito, ou seja, ao objeto. 
Diante do exposto, e levando-se em conta as especificidades da atividade de estudo, perguntamos: Em qual momento do desenvolvimento ela se torna mais importante?

Leontiev (2004) assinalou que em cada período do desenvolvimento tem-se uma atividade que é mais importante para o desenvolvimento psíquico da pessoa. Dessa maneira, a atividade de estudo está diretamente ligada ao processo de ensino e aprendizagem e, portanto, é a atividade dominante para os alunos em idade escolar.

O estudo, quer dizer aquela atividade em cujo processo transcorre a assimilação de novos conhecimentos e cuja direção se constitui o objetivo fundamental do ensino, é a atividade dominante nesse período. Durante ela tem lugar uma intensa formação das forças intelectuais e cognoscitivas da criança. A importância primordial da atividade de estudo está determinada, também, porque através dela se mediatiza todo o sistema de relações da criança com os adultos que a rodeiam, incluindo a comunicação pessoal na família (ELKONIN, 1987, p. 119, tradução nossa).

Embora os estudos do autor tenham chegado aos resultados que determinam a idade escolar como o período ao qual a atividade de estudo exerce maior influência no desenvolvimento psíquico, Davídov e Márkova (1987) acreditam que a atividade de estudo perpassa por todos os períodos do desenvolvimento, mas com determinadas especificidades.

A idade escolar inicial se caracteriza pela introdução dos alunos à atividade de estudo, ao domínio, por parte destes, de todos seus componentes; aqui a atividade tem importância orientadora. Na idade escolar média tem lugar o domínio, por parte da criança, da estrutura geral da atividade de estudo, a formação de seu caráter voluntário, a tomada de consciência das particularidades individuais do próprio trabalho de estudo, a utilização dessa atividade como meio para organizar as interações sociais com outros escolares. A idade escolar avançada se caracteriza pela utilização da atividade de estudo como meio para a orientação e a preparação profissional, o domínio dos meios de atividade de estudo autônoma e da auto-educação e também a passagem da assimilação da experiência socialmente elaborada da atividade de estudo, fixada nos manuais, ao seu enriquecimento, ou seja, à atividade cognoscitiva e investigativa criadora (DAVÍDOV; MÁRKOVA, p. 330, tradução nossa).

A atividade de estudo perpassa três períodos do desenvolvimento humano - a idade escolar inicial, final e avançada - nos quais podemos identificar os alunos das séries iniciais e finais do Ensino Fundamental e a adolescência, respectivamente.

Na primeira etapa, a atividade de estudo manifesta-se de forma introdutória e se configura no meio pelo qual predominantemente a criança estabelece relações com o mundo, o que impulsiona as transformações e o desenvolvimento. Na seguinte, ao se preparar para adentrar na adolescência, a criança passa a dominar toda a estrutura da atividade de estudo, bem como passa a atuar de forma voluntária, compreendendo as particularidades individuais de cada ação e diferentes formas de realizar as tarefas. Por último, na adolescência, o aluno passa a ser preparado para a vida profissional e, por isso, a atividade de estudo se manifesta de forma mais autônoma, investigativa e criadora (DAVÍDOV; MÁRKOVA, 1987). 


\section{A Estrutura da Atividade de Estudo}

A estrutura da atividade de estudo, tal como Davídov (1988) delineou em suas pesquisas experimentais, apresenta algumas ações imprescindíveis para que haja impacto no desenvolvimento dos escolares. Davídov (1988, p. 181, tradução nossa) enumera as ações na seguinte ordem:

[...] transformação dos dados da tarefa como fim de expor a relação universal do objeto estudado; modelação da relação diferenciada em forma objetal, gráfica ou por meio de letras; transformação do modelo da relação para estudar suas propriedades em "forma pura"; construção do sistema de tarefas particulares a resolver por um procedimento geral; controle sobre o cumprimento das ações anteriores; avaliação da assimilação do procedimento geral como resultado da solução da tarefa de estudo dada.

Como podemos perceber, a estrutura da atividade de estudo é composta por seis diferentes ações que perpassam diversos níveis de generalização e de relação do sujeito com o objeto de estudo.

A primeira ação consiste em uma análise inicial do objeto de estudo em sua forma objetal-sensória, que busca identificar, por meio de suas diferentes transformações, a relação universal entre o objeto e seu conteúdo teórico. A busca por essa relação forma "[...] o conteúdo da análise mental, a qual em sua função de estudo aparece como o momento inicial do processo de formação do conceito requerido" (DAVÍDOV, 1988, p. 182, tradução nossa).

Quanto à segunda ação da atividade de estudo - a modelação objetal -, podemos compreendê-la como sendo o momento em que o aluno fixa a relação universal, obtida na primeira ação, em objetos, símbolos, signos e demais representações materiais. Isto é, o modelo de estudo é a representação materializada das características internas e traços essenciais e universais do objeto estudado. "É importante assinalar que os modelos de estudo constituem um elo internamente imprescindível no processo de assimilação dos conhecimentos teóricos e dos procedimentos generalizados de ação" (DAVÍDOV, 1988, p. 182, tradução nossa).

A ação seguinte a ser desenvolvida pelo estudante consiste na transformação do modelo de estudo com a intenção de estudar a propriedade da relação universal anteriormente revelada no objeto.

Esta relação, nos dados reais da tarefa, parece estar "oculta" em muitos traços particulares que, em conjunto, dificultam seu exame especial. No modelo, em transformação, essa relação se faz visível e se pode dizer que aparece em "forma pura". Por isso, transformando e reconstruindo o modelo, os escolares têm a possibilidade de estudar as propriedades da relação universal como tal, sem o "ocultamento" produzido por circunstâncias presentes. O trabalho com o modelo é um processo pelo qual se estudam as propriedades da abstração substancial da relação universal (DAVÍDOV, 1988, p. 183, tradução nossa).

A transformação do modelo é um caminho que o aluno deve percorrer para que a relação universal do objeto, estudado anteriormente, sirva como base para formar procedimentos gerais de solução de tarefas e, a partir disso, chegar ao núcleo do objeto, 
ou seja, seu conceito generalizado e abreviado. Para se chegar a esse resultado, porém, é necessário extrair as múltiplas manifestações particulares do objeto, que somente se constituem nas relações com diferentes tarefas de estudo particulares.

Por essa razão, a quarta ação configura-se na dedução e construção de tarefas particulares, o que possibilita aos alunos a concretização da

[...] tarefa de estudo inicial e a convertam na diversidade de tarefas particulares que podem ser resolvidas por um procedimento único (geral), assimilado durante a realização das ações de estudo anteriores. $O$ caráter eficaz deste procedimento se verifica, justamente, na solução de tarefas particulares; os escolares as enfocam como variantes da tarefa de estudo inicial e, imediatamente, como se fosse "de golpe", separam em cada uma a relação geral, orientando-se pela qual podem aplicar o procedimento geral de solução anteriormente assimilado (DAVÍDOV , 1988, p. 183, tradução nossa).

Essas ações de estudo possibilitam aos estudantes o descobrimento das condições de surgimento do conceito por eles assimilado. Há uma compreensão de todo o processo lógico e histórico da constituição do conceito, no qual estão expressas as múltiplas determinações que a ele se vinculam. É como se o aluno, sob a orientação do professor, reconstruísse o conceito em sua essência.

Para se concretizar toda a estrutura da atividade de estudo, são necessárias as ações de controle e avaliação responsáveis por garantir o processo de assimilação dos conhecimentos por parte dos alunos. Por um lado, temos o controle que

[...] consiste em determinar a correspondência entre outras ações de estudo às condições e exigências da tarefa de estudo. Permite ao aluno, ao mudar a composição operacional das ações, revelar sua relação com umas e outras peculiaridades dos dados da tarefa a ser resolvida e do resultado a ser obtido. Graças a isto, o controle assegura a requerida plenitude na composição operacional das ações e a forma correta de sua execução (DAVÍDOV, 1988, p. 184, tradução nossa).

Uma ação de controle, de acordo com Elkonin (1999), consiste na comparação de uma ação realizada por um aluno com uma imagem ou representação mental aproximada do que se espera alcançar. É necessário o professor desenvolver um protótipo que não reproduza totalmente a ação do aluno, mas que contenha "[...] pontos de referência de modo que uma ação de controle possa ser realizada com base em uma comparação com esses pontos de referência até que a ação desejada, para cuja execução do método particular foi aplicada, tenha sido realizada" (ELKONIN, 1999, p. 90, tradução nossa).

A realização da ação de controle é extremamente importante para que o aluno possa acompanhar o desenvolvimento de determinadas tarefas de estudo, bem como verificar se está de acordo com o protótipo esperado. Graças à realização do controle é garantido o caráter voluntário da atividade de estudo, no qual o estudante consegue realizar suas tarefas sem perder de vista o conceito e sua representação.

Por último, a ação de avaliação é o componente que permite ao professor identificar se o conteúdo e os conceitos foram assimilados ou não pelo aluno. Essa ação possibilita, também, avaliar "[...] o procedimento geral de solução da tarefa de estudo dada, se o resultado das ações de estudo corresponde (e em que medida) ou não ao seu objetivo final" (DAVÍDOV, 1988, p. 184, tradução nossa). Nesse sentido, a avaliação se 
configura em um exame qualitativo e substancial do resultado da assimilação do conceito, informando aos agentes do processo se a atividade de estudo foi concretizada satisfatoriamente.

\section{CONSIDERAÇÕES}

Chegamos ao final deste ensaio teórico no qual pudemos esboçar a nossa compreensão acerca da atividade de estudo e todos os seus componentes, que vão desde os seus princípios gerais, delineados por Leontiev, até a sua estruturação e perspectivas, definidas por Elkonin e Davidov .

Consideramos que a atividade de estudo deve ser apropriada e empregada pelos professores em sua prática em sala de aula, uma vez que, além de ter como conteúdo o conhecimento teórico, é uma atividade que tem um caráter principal na vida das crianças em idade escolar e, por isso, criar motivos que coincidem com o objeto de estudo do conteúdo escolar é um princípio fundamental para o desenvolvimento psíquico dos estudantes.

A atividade de estudo, em toda a sua estrutura, possibilita ao estudante o desenvolvimento de ações mentais acerca dos objetos circundantes. Esse princípio fundamental para o desenvolvimento modifica a forma como o aluno interage com o mundo, como também modifica o meio que o circunda. Isso consiste no cerne da perspectiva histórico-cultural que, por meio desse movimento dialético, sempre pressupõe uma mudança ou superação das condições que estão postas objetivamente.

Embora a atividade de estudo seja a mais importante para o desenvolvimento de estudantes em idade equivalente ao Ensino Fundamental Brasileiro, é importante enfatizar que esse tipo de atividade perpassa todos os estágios e períodos de desenvolvimento e, nesse caso, a atividade de estudo diferencia-se das atividades de jogo e de trabalho, justamente por seu caráter criativo e transformador do sujeito envolvido.

Dessa forma, como expressão do processo de formação do pensamento teórico e consequente modificação interna dos estudantes, Davidov delineou um conjunto de ações no âmbito da atividade de estudo que são fundamentais para o processo educativo: 1) análise inicial do objeto de estudo, buscando identificar sua relação universal com o conteúdo teórico; 2) modelação objetal e representação material e materializada do conceito; 3) transformação do modelo para analisar suas propriedades em "forma pura"; 4) elaboração de tarefas e ações de estudos particulares, com vistas a reconstruir o conceito em sua essência; 5) controle sobre a realização das tarefas e ações anteriores; e 6) avaliação da assimilação como resultado dos processos anteriores.

Esses princípios teóricos identificados nas obras dos principais autores soviéticos ligados à atividade de estudo, possibilitam uma ampliação nas discussões sobre a educação, sobretudo na área do ensino, apresentando diretrizes gerais para uma possível organização do conteúdo escolar e difusão desse referencial, seja para o emprego prático em sala de aula ou para futuras pesquisas e desdobramentos teóricos.

\section{REFERÊNCIAS}

DAVÍDOV, V.; MÁRKOVA, A. La concepción de la actividad de estudio de los escolares. In: SHUARE, M. La Psicología evolutiva y pedagógica en la URSS - Antología. Moscú: Progreso, 1987. p. 316-337.

DAVÍDOV, V. V. La enseñanza escolar y el desarrollo psíquico: investigación psicológica teórica y experimental. Moscu: Editorial Progreso, 1988. 


\section{\& Contexto}

Antonio Paulino de Oliveira Junior - José Carlos Miguel

DAVÍDOV, V. V. O que é a atividade de estudo. Revista Escola Inicial, n. 7, p 1-7, 1999. (Tradução do Russo de Ermelinda Prestes).

DAVÝDOV. V. V. Tipos de generalización en la enseñanza. Ciudad de la Habana: Editorial Pueblo y Educación, 1982.

ELKONIN, D. B. On the structure of learning activity. In: Journal of Russian and East European Psychology, v. 37, n. 6, p. 84-92, nov./dez. 1999.

ELKONIN, D. B. Sobre el problema de la periodización del desarrollo psíquico en la infancia. In: SHUARE, M. La Psicología evolutiva y pedagógica en la URSS - Antología. Moscú: Progreso, 1987. p. 104-124.

LEONTIEV, A. N. O desenvolvimento do psiquismo. 2. ed. São Paulo: Centauro, 2004.

LEONTIEV, A. N. Uma contribuição à teoria do desenvolvimento da psique infantil. In: VIGOTSKII, L. S.; LURIA, A. R.; LEONTIEV, A. N. Linguagem, desenvolvimento e aprendizagem. Tradução Maria da Penha Villalobos. São Paulo: Ícone, 2001. p. 59-83.

REPKIN, V. V. Ensino desenvolvente e atividade de estudo. In: Ensino em Re-Vista. v. 21, n. 1, p. 85-99, jan./jun. 2014.

VIGOTSKI, L. S. Quarta aula: a questão do meio na pedologia. Tradução Márcia Pileggi Vinha. Revisão Max Welcman. In: Psicologia - USP [on-line]. v. 21, n. 4, p. 681-701. 2010. Disponível em: http://www.revistas. usp.br/psicousp/article/view/42022. Acesso em: 4 abr. 2017. 